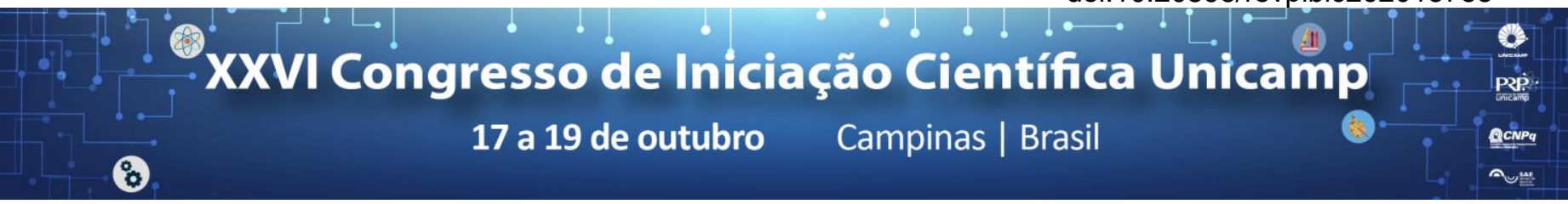

\title{
Análise Termodinâmica de Sistemas de Refrigeração com Injeção de Vapor e Tanque Flash
}

\section{Larissa P. Titato*, Amanda K. Machado, José Vicente H. d'Angelo - Faculdade de Engenharia Química}

\section{Resumo}

Este projeto apresenta uma análise termodinâmica do desempenho de ciclos de refrigeração com injeção de vapor e tanque flash, utilizando refrigerantes puros NH3, R600a e R32 e misturas CO2/NH3, NH3/R600a e R1270/R600a. Estes sistemas foram simulados e analisadas as influências da composição das misturas e da razão de expansão na válvula superior sobre: COP, vazão mássica de refrigerante, "glides" de temperatura e potência de compressão.

\section{Palavras-chave:}

Refrigeração, Simulação, Tanque flash.

\section{Introdução}

Sistemas de refrigeração apresentam vasta aplicação nos ramos industrial, residencial e comercial. São grandes consumidores de energia, requerendo operação em condições otimizadas, devido aos impactos ambientais e econômicos. Nesse contexto, ressalta-se a importância do estudo de diferentes configurações dos sistemas de refrigeração e da utilização de novos fluidos refrigerantes, com destaque para a aplicação do sistema de injeção de vapor com tanque flash (FTVI).

O projeto teve como objetivo o estudo de refrigerantes puros e misturas para aplicação em um sistema de injeção de vapor com tanque flash. Foram analisados os refrigerantes puros $\mathrm{NH}_{3}, \mathrm{R} 600 \mathrm{a}$ e $\mathrm{R} 32$ e as misturas $\mathrm{CO}_{2} / \mathrm{NH}_{3}, \quad \mathrm{NH}_{3} / \mathrm{R} 600 \mathrm{a}$ e R1270/R600a, sendo suas escolhas fundamentadas em parâmetros ambientais (ODP e GWP), operacionais e econômicos.

Os sistemas foram simulados em diferentes condições operacionais por meio do software Aspen Hysys ${ }^{\circledR}$, sendo o desempenho avaliado com base no parâmetro COP ("Coefficient of Performance"). A simulação destes sistemas permite uma análise ampla da influência de diferentes parâmetros operacionais, frente às variações na composição das misturas e na razão de expansão da válvula superior do sistema.

\section{Resultados e Discussão}

São apresentados os resultados para o sistema $\mathrm{CO}_{2} / \mathrm{NH}_{3}$, o qual obteve o melhor desempenho. A Figura 1 apresenta um esquema do ciclo e as Figuras 2 e 3 o comportamento do COP e da vazão mássica, respectivamente, ambos em função da composição da mistura e das razões de expansão da válvula.

O melhor desempenho é obtido para uma fração mássica de $\mathrm{NH}_{3}$ entre 0,3-0,4 com uma abertura de $50 \%$ na válvula, sendo cerca de $12 \%$ superior ao obtido para o ciclo de compressão de vapor convencional (VCC).

Para a vazão mássica, observa-se seu decaimento com o aumento da fração mássica de $\mathrm{NH}_{3}$, uma vez que esta substância possui um maior calor latente de ebulição em relação ao $\mathrm{R600a}$. Desse modo, aumentar sua fração permite uma melhor troca térmica, exigindo uma menor vazão de refrigerante (d'Angelo et. al., 2016).

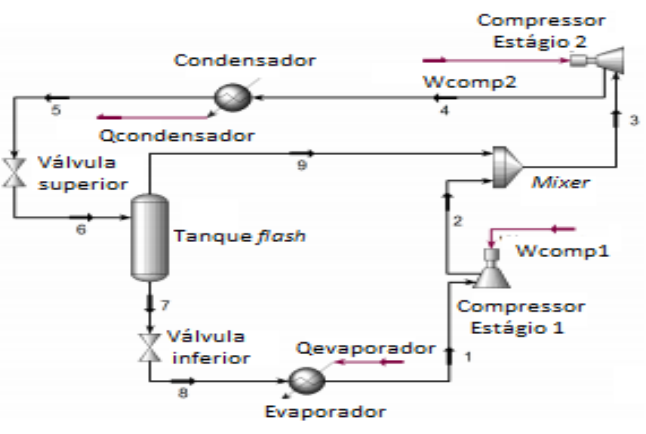

Figura 1: Esquema do ciclo simulado.

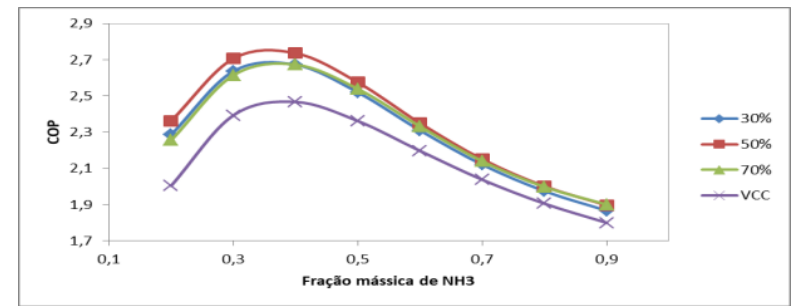

Figura 2: COP em função da fração mássica de NH3 e das difentes razões de expansão na vávula.

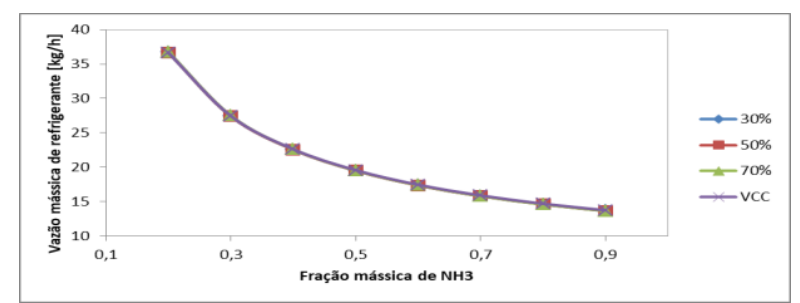

Figura 3: Vazão mássica de refrigerante em função da fração de NH3 e das razões de expansão na vávula.

\section{Conclusões}

Nota-se que o COP apresentado pelo sistema FTVI é superior ao obtido com o sistema VCC. Existe uma relação inversamente proporcional entre a vazão mássica e a fração de amônia, devido ao seu maior calor latente. Por fim, o melhor desempenho encontrado refere-se a uma fração de $\mathrm{NH}_{3}$ entre $0,3-0,4$ para uma abertura de válvula de $50 \%$.

\section{Agradecimentos}

À FAPESP (Processo 2016/25471-4).

${ }^{1}$ D'Angelo, J. V. H.; Araujo, H.V.; Ling, J.; Aute, V.; Radermacher, R. . International Refrigeration and Air Conditioning Conference, 2016. 